\title{
"TOMAI, COMEI; ISTO É MEU CORPO": A RESISTÊNCIA DO GROTESCO ${ }^{1}$
}

\author{
Prof. Dr. Antônio Vargas Sant'Anna² \\ Karina Pedigoni Segantini ${ }^{3}$
}

\section{Resumo:}

Este artigo procura rever o percurso da categoria estética do grotesco na sociedade ocidental a partir de associações teóricas de alguns pesquisadores especializados como Mary Russo, Mikhail Bakhtin, Muniz Sodré e Wolfgang Kayser. Também, discute as relações e implicações do grotesco com as temáticas: sexo e violência na arte contemporânea, enfatizando obras da artista Márcia X.

\section{Palavras-chave:}

Grotesco; Arte Contemporânea; Márcia X

A inconstante forma do grotesco nos acompanha desde os primórdios que habitavam a dura lei hierárquica da natureza, que, de forma ambígua, tira e dá vida, é ventre e cova, violenta e benévola. $\mathrm{Na}$ vida contemporânea ocidental, transitamos constantemente por esses altos e baixos, porém não reagimos de forma tão natural aos últimos. O corpo materno, durante a gestação, sofre brutas mudanças, tornando-se muitas vezes, repugnante perturbando a imaginação alheia. O aparelho reprodutivo feminino é infinitamente complexo. Sua albumina do sangue, seus dejetos uterinos e as mornas placentas são transformados pelo sistema social num felpudo e dócil parto rosa - bebê. A menstruação e o parto , assim como a morte, são tabus considerados, um espetáculo de horror e miséria perante a sociedade. Surgem dessa forma, os hospitais e os produtos descartáveis. O espanto e o terror que estão presentes na origem e morte

\footnotetext{
${ }^{1}$ Projeto Imagética Grotesca - CEART - UDESC

${ }^{2} 2$ Professor do Departamento de Artes Visuais. Diretor do Centro de Artes da UDESC.

${ }^{3} 3$ Bolsista - PROBIC - UDESC
} 
humana são travestidos, pois aquilo que temos consciência poderia nos levar à loucura. A matriz humana, assim como a natureza que fazemos parte, é grotesca.

A vida civilizada ocidental exige um estado de ilusão para escapar do medo primitivo existencial. Paglia (1992) acredita que a sociedade não seja criminosa, mas que a força desvela o crime. Defende a versão de que o homem seja um receptor da agressão originada pela própria natureza e compara esta questão com a vontade de poder de Nietzsche dialogando também, com a idéia de Marquês de Sade o qual crê, segundo Paglia, que retornar a natureza é estimular o desejo e a violência. Paglia comenta:

O reconhecimento é cognoscência ritual, uma compulsão de repetição. Dizemos que a natureza é bela. Mas esse julgamento estético, que nem todos os povos têm partilhado, é outra forma de defesa, desgraçadamente inadequada para abranger a totalidade da natureza. O que é bonito na natureza se limita à fina película do globo sobre o qual nos amontoamos. É só arranhar essa película, que surgirá a feiúra daimônica da natureza. (PAGLIA, 1992: 17)

O vocábulo Grotesco teve origem na língua italiana, la grottesca e grottesco, derivados de grotta (gruta). O termo foi utilizado para denominar objetos ornamentais e pinturas encontrados em escavações feitas em Roma no final do século XV nos subterrâneos das Termas do Tito e em outras regiões próximas da Itália. Suas formas eram inacabadas, abertas e fantásticas, metamorfoses de figuras humanas com animais, plantas e espaços, fugindo da representação real do mundo.

Mary Russo (2000), teórica do grotesco, afirma que a categoria como tal só surgiu a partir de interesses por tratados estéticos como De Architectura de Vetruvius, que colocava o grotesco em oposição ao estilo clássico. Dessa forma, era considerado como algo frívolo, artificial, irracional, repudiado pelas normas das artes clássicas e da natureza. A autora também acredita que a categoria apenas surgiu em relação às normas com as quais excedia. Adverte que este evento não foi uma descoberta e muito menos a origem do grotesco, pois já havia a identificação de objetos e desenhos por historiadores anteriores a Roma clássica.

Já para Wolfgang Kayser (1986), o grotesco ornamental possui no Renascimento, uma significação lúdica, alegre, leve e fantasiosa, porém angustiante e 
sinistra com um mundo fora de ordem natural. Destacam-se, dessa forma, os ornamentos grotescos de Rafael nas pilastras papais no Palácio do Vaticano. No século $\mathrm{XVI}$, o grotesco é aceito como substantivo para designar a arte ornamental grotesca e desdobra-se em adjetivos, que acaba por se desvincular de seu objeto concreto. Deste modo, tornam-se características do grotesco o ridículo, deformado, assustador, desordenado, desproporcional, inumano e monstruoso. No século XVIII, o novo gosto classicista rejeita o grotesco por considerá-lo algo imaginado, sonhado, fantasiado, fora de motivos reais, sem significado, de mau gosto, distante da inteligência e da verdade.

Uma das correntes discursivas para a categoria do grotesco é a teoria da carnavalização, tendo como principal porta voz Mikhail Bakhtin (1993). Essa corrente é de cunho histórico, utilizada para conceitualizar formações e conflitos sociais, ou de esfera política. Assim, o corpo grotesco seria um corpo social, um princípio material corporal contido no povo e não no ego burguês ou no indivíduo biológico. Este corpo, para ele, cresce e se renova constantemente, mistura-se com o mundo, animais e objetos. É identificado com o estrato inferior do corpo, o degradado, a morte, o nascimento, ao imundo, um corpo mutável, aberto, protuberante, irregular, secretante, múltiplo. Diferente da estética e do corpo clássico que é fechado, acabado, contido, simétrico, que se identifica com a cultura oficial e superior, com o racionalismo, individualismo e inspirações burguesas.

Os discursos sobre o carnavalesco, para Russo (2000), deslocam para o campo social e para o sistema simbólico, questões como a retenção e exposição corporais, marginalidade, abjeção, disfarces e mascaradas de gênero, paródia e excesso. Também, no livro: O Grotesco Feminino, risco excesso e modernidade, Russo (2000) cita Michel Foucault (1975), na introdução de On the Normal and the Pathological, que complementa sua reflexão: "o poder da normalização impõe homogeneidade; mas individualiza, possibilitando medir lacunas, determinar níveis, fixar especialidades e tornar as diferenças úteis adequando-as umas às outras."(Foucault apud RUSSO, 1992:23) Dessa forma, para Russo, o corpo grotesco, seria um corpo que surge como um desvio da norma, um espaço de risco e abjeção.

Outra corrente debatida é o grotesco como estranho. Este se comunica com a psique, com o mundo introspectivo, interior, individualizado, fantasioso, que corre o risco de inércia social. Seria para Russo (2000), uma "projeção cultural de um estado 
interior". Essa imagem corporal ambígua, monstruosa, deformada, excessiva, desprezível, surge de uma divisão entre as ficções discursivas do corpo biológico e da lei. Observa-se em casos analisados sob o cânone freudiano a presença dessas características grotescas em mutilações, distorções, duplos, aparições, próteses e hibridismo. Já Kayser (1986), contribuiu para a corrente do grotesco estranho, através da recepção da obra, do psicológico, ampliando a idéia de estranheza adicionando a alienação de um mundo que se tornou estranho.

Russo (2000) conecta o grotesco com "o estranho" freudiano. O duplo estranho é dividido em dois momentos psíquicos: o narcisismo primário e infantil e o desenvolvimento da consciência posterior da vida. O olhar crítico sobre o antigo narcisismo superado gera vergonha, remorso e esperança, numa espécie de nostalgia do futuro com efeitos do estranho, apegados na fantasia de futuros possíveis, mas não realizados. Assim, Russo os relaciona sugerindo uma apropriação ética do grotesco, como uma categoria já superada assim também como o sublime.

Freud era definitivamente e notavelmente imune ao momento sublime, cujo disfarce "oceânico" e demoníaco ele expôs com brilhantismo. Para nos agradar, o sublime deve agora ser assumido, reduzido e parodiado como grotesco, de uma certa forma cercado de ironia para nos garantir de não sermos adolescentes de imaginação fértil. (WEISKEL apud Russo, 2000:47)

Desse modo, Russo (2000) acrescenta: "O intenso desapontamento e o estado de espírito de vergonhosa abjeção que ultrapassa o cenário narcisista [...] evocam ansiedades, sarcasmos e constrangimentos do grotesco nos seus disfarces pósromânticos ou modernistas". (RUSSO, 2000:47, 48)

Já Muniz Sodré (1973) alia o grotesco à cultura de massa nacional, que, através da atmosfera psicossocial é retirado de seu contexto crítico, atua com finalidade de compensação para a angústia do homem moderno. Sodré conceitua a categoria estética nesse contexto como:

[...] o fabuloso, o aberrante, o macabro, o demente. [...] o grotesco é uma aberração de estrutura ou de contexto [...] o miserável, o estropiado, são grotescos em face da sofisticação da sociedade de consumo, especialmente quando são apresentados em forma de espetáculo. A “estranheza” que caracteriza o grotesco coloca-o perto do 
cômico ou do caricatural, mas também do Kitsch. [...] o grotesco é um mundo distanciado, daí a sua afinação com o estranho e o exótico. (SODRÉ, 1973:39)

O corpo grotesco, se baseado em Bakhtin (1993), durante os carnavais, jamais era distanciado da platéia e nem era visto como objeto, como nos espetáculos. De forma imaginária, platéia e artistas faziam parte de um todo incompleto. As diferenças sociais eram invertidas ou indefinidas, sem fronteiras e hiperbolizado. Diferente do corpo dos cânones modernos, também, de acordo com o realismo grotesco de Bakhtin, encontra-se em diferentes estágios de crescimento, contornos, degeneração, anomalias, prótese, perda e excesso. O espetáculo, ao contrário do carnaval, seria uma maneira objetificada de olhar o mundo à distância.

\section{O sexo e a violência na arte contemporânea}

Uma das teorias antropológicas mais aceitas no âmbito acadêmico sustenta que a arte feita no período pré-histórico era um objeto de magia para conseguir o que desejava, assim sendo, não eram para serem "apreciadas" e sim utilizadas. Segundo Paglia (1992), o olhar sobre o belo surge por criação do homem para dar forma, limites, simetria e proporção a natureza:

O olho é peremptório em seus julgamentos. Decide o que ver e por quê. Cada um de nossos olhares é tanto exclusão quanto inclusão. Nós escolhemos, comentamos e realçamos. Nossa idéia do belo é uma noção limitada, que não se pode aplicar ao submundo metafórico da terra, um domínio cataclísmico de violência ctônica. Preferimos não ver essa violência em nossos passeios diários. Toda vez que dizemos que a natureza é bela, estamos fazendo uma prece, dedilhando as contas de nossas preocupações. (PAGLIA, 1992:26)

Paglia (1992:38) também comenta: “[...] O primeiro artista foi um sacerdote tribal lançando um sortilégio, fixando a daimônica energia da natureza num momento de perpétua imobilidade. [...]" Dessa forma, a arte fascina através da contemplação como num ato de magia. Longe da moral, ela é ordem, porém não necessariamente, 
justa, bela e boa. Com o deslocamento da arte para a periferia da cultura, esta, nos tempos modernos, muitas vezes se torna agressiva e compulsiva.

O dionisíaco e apolíneo, segundo Paglia (1992), são os dois princípios ocidentais que governam as personas sexuais presentes na vida e na arte. A cultura do ocidente oscila entre um e outro e ambos lutam constantemente pela vitória e afirma:

Dioniso é identificação, Apolo objetificação. Dioniso é o empático, a emoção simpática que nos transporta para dentro de outras pessoas, outros lugares ou tempo. Apolo é o separatismo duro, frio, da personalidade e do pensamento categórico do Ocidente. Dioniso é energia, êxtase, histeria, promiscuidade, emocionalismo - indiscriminação indiferente da idéia ou prática. Apolo é obsessividade, voyeurismo, idolatria, fascismo frigidez e agressão do olho, petrificação dos objetos. [...] Dioniso é energia desenfreada, louca, rude, destrutiva, estróina. Apolo é a lei, a história, a tradição, a dignidade e a segurança do costume e da forma. Apolo congela, Dioniso dissolve. Apolo diz "Pára!". Dioniso diz “Anda!"[...] Dioniso introduz na matéria movimento e energia: os objetos são vivos, e as pessoas bestiais. Apolo imobiliza os vivos em objetos de arte ou de contemplação. A objetificação apolínea é fascista, mas sublime, ampliando o poder humano contra a tirania da natureza. [...] " (PAGLIA, 1992:99, 100, 106)

Atualmente, a representação e apresentação do grotesco em cenas extremas são constantemente abordadas por vários artistas contemporâneos. Se por um lado bloqueia a nossa imaginação, por outro estimula a reflexão, perante uma cultura fascinada pelo trauma que estabelece uma nova forma estética e ética da representação.

Nesse contexto artístico, tendo o elemento sexual como principal temática por via do grotesco insere-se Márcia X. A artista carioca, que atuou desde a década de 80 até 2005, ano em que faleceu, questiona por meio de instalações, objetos, vídeos e performances, o papel do artista e da arte na sociedade, através do humor, estranhamento, sarcasmo e provocação. Na década de 90, a artista transforma objetos pornográficos em objetos infantis e objetos infantis em pornográficos. Também se apropria de artigos religiosos dando-lhes conotações antagônicas. Surge dessa estratégia artística a Fábrica Fallus (1993-2005), Os Kaminhas Sutrinhas (1995) e Desenhando com Terços (2000-2002), mesclando elementos de códigos morais e sociais de conotações opostas. As últimas criações de Márcia $\mathrm{X}$ aproximam-se de elementos ritualísticos presentes na religiosidade brasileira e obsessões sociais que contaminam a 
artificialidade do universo feminino, como a beleza, fantasias sexuais, atividades domésticas, alimentação, rotina e consumo.

De forma provocativa, Márcia X une em Fábrica Fallus e Desenhando com Terços o profano e o sagrado, interage com o pensamento de Paglia (1992:33) quando esta diz: "Tudo que é sagrado e inviolável provoca profanação e violação. Todo crime que pode ser cometido, será. [...] " A artista, na série Fábrica Fallus utiliza-se de inúmeros pênis de plástico comprados em Sex Shop, enfeita-os com brilhantes artifícios de beleza kitsch encontrados no Saara do Rio de Janeiro como medalhas, espelhos, pompons e rendas. Dá-lhes vida através de som e movimento. Passam de pênis anônimos e impessoais, passivos de prateleiras às pessoas reconhecidas pelo sistema social. Vibrantes e ativos percorrem e esbarram-se no chão dos espaços expositivos. Márcia X repete algo que já é recorrente na cultura ocidental: objetificar pessoas e dar vida e idolatrar objetos.

Já a polêmica obra censurada e exposta no CCBB (Centro Cultural Banco do Brasil) Desenhando com terços, da exposição Erótica - Os sentidos da arte (2006) teria como idéia inicial, o acompanhamento da ação de Márcia $\mathbf{X}$ pelo espectador, enquanto esta preenche obsessivamente o chão do local expositivo com centenas de terços católicos. São desenhos em formato de pênis, proporcionando no final, uma complexidade de tramas abstratas que permanecem em exposição após a ação. Segundo a artista, a performance poderia durar dias.

O trocadilho entre sexo e religião em Márcia $\mathbf{X}$ lança luz a um passado obscurecido pelas convencionais poeiras temporais em que a apropriação do Cristianismo sobre o paganismo era comum. Objetivando atrair adeptos, o Cristianismo passa a adotar imagens e ritos pagãos. No início da Idade Média, a Igreja fazia coincidir as festas pagãs com as cristãs e tinham relações com os cultos cômicos com finalidade de cristianizá-los, pois a cultura popular era muito forte e teria que ser considerada para que os detentores do poder alcançassem seus fins. Nos dias de carnaval, o homem medieval se liberta e domina o medo através da vitória sobre os terrores do além, da morte, além das formas de poder dos soberanos terrestres e sua aristocracia social que oprime e limita. Brinca-se e faz pouco do temível. Assim como Márcia X e os excêntricos britânicos irmãos Chapman. Estes, por sua vez, unem partes de corpos infantis, principalmente, criando seres híbridos e complexos, sexualmente polimórficos, 
unidos por órgãos genitais, prontos para serem penetrados como as bonecas do Sexy Shop. Essas estranhas combinações físicas esculturais, não são tão diferentes das antigas formas grotescas, encontradas nas escavações de Roma e das relíquias de esquartejamento físico dos santos católicos.

Essas relíquias, com partes dos corpos de santos espalhados pela França, influenciam as imagens corporais grotescas. As Igrejas católicas italianas mergulhadas num mar de sangue, lágrimas, torturas e êxtase são fartam-se dos antigos mistérios pagãos baseados no sexo e no sadomasoquismo. Exemplos são os cadáveres de santos envidraçados, as flechas trespassadas no peito nu de São Sebastião, Santa Luzia segurando seus próprios olhos no prato, pedaços de ossos de braços em dourados relicários.

Um costume comum e indispensável para a personificação nos rituais pagãos destinados à Grande Mãe era a autocastração, a amputação de seios, o sacrifício de animais, talhos e a autoflagelação, que dramatizavam cruelmente a fertilização animal da deusa. Esse tipo de comportamento é reconhecido por Paglia (1992), atualmente, na forma do sadomasoquismo sexual, que tanto é associado ao pervertido. Nas religiões de mistérios, que tanto influenciou o Cristianismo, era comum que o fiel imitasse e buscasse união com seu deus. Também, a autora comenta:

O princípio violento do culto de Dioniso é o sparagmós, que em grego quer dizer "rasgar, despedaçar, estropiar", e, secundariamente, "convulsão, espasmo". O corpo do Deus, ou um substituto humano ou animal, é feito em pedaços, que são comidos ou espalhados como sementes. A omofagia, o comer ritual de carne humana crua, é a assimilação e internalização da divindade. A antiga religião de mistérios baseava-se na imitação do deus pelo fiel. [...] Antes de ser preso, Jesus rasga o pão da Páscoa para seus discípulos: "Tomai, comei; isto é meu corpo" (Mateus 26:26). Em todo ofício cristão, óstia e vinho, transforma-se no corpo e sangue de Cristo, consumidos pelo fiel. No catolicismo, isso não é simbólico, mas literal. Transubstanciação é canibalismo. [...] (PAGLIA, 1992: 98,99)

Ações de automutilações acompanhadas de tabus sexuais e escatológicos ainda hoje, não perderam suas forças pagãs. Na forma da arte contemporânea, são seus representantes: David Nebreda, que experimenta seu torço com talhos e rasgos por meio de práticas imperativas e disciplinadoras. Seus registros fotográficos lembram 
imagens do corpo dilacerado de Cristo, chicoteado e crucificado. Também, Herman Nitsch, Otto Mühl, Günter Brus e Rudolf Schwarzkogler, pertencentes acionismo vienense (1965-1970), que focavam suas ações performáticas na automutilação, no auto-sacrifício e na quebra de tabus por meio do sexo explícito, ingestão de urina e vômito, projeção de fezes e matança de animais. Herman Nitsch descreve suas sangrentas performances ritualísticas inspiradas em ritos pagãos e cristãos como "uma forma estética de oração" ( NITSCH apud Goldberg, 2006:153), buscando através do medo, do terror e da compaixão, recuperar os instintos agressivos reprimidos pela mídia; as mutilações performáticas semelhantes a desastres levaram Rudolf Schwarzkogler à morte em 1969; Marina Abramovic também colocou sua pele em risco na performance Ritmo Zero (1974): a artista doou passivamente seu corpo para ser manipulado junto a outros objetos sobre uma mesa. A performance foi encerrada depois de uma luta entre seus espectadores (torturadores e protetores) com uma arma carregada, pega sobre a mesa, apontada para sua cabeça.

Além disso, essas antigas ações pagãs estão presentes na performance Shoot (1971) de Chris Burden, em que o amigo atira em seu ombro; no frágil corpo submetido a sucessivas e obsessivas cirurgias estéticas da artista francesa Orlan e, por fim, nos assépticos e ideais cadáveres plastinizados do alemão Gunther von Hagens, que novamente, torna-se evidente a mania ocidental: transformar pessoas em objetos, na ocasião, objetos de arte.

Já a imagem da santa confeccionada com excremento de elefante do inglês Chris Ofili, que pertenceu à exposição Sensation (Londres: 1997 e Nova York: 1998), remete à afirmação de Santo Agostinho quando este comenta: "Nascemos entre fezes e urina”. Em Nova York, a obra causou inquietude aos visitantes e indignação da Igreja e Estado.

[...] O cristianismo fez um ajuste após o outro, absorvendo engenhosamente a oposição (como durante o Renascimento italiano) e diluindo seu dogma para acompanhar as mudanças dos tempos. Mas chegou a um ponto crítico. Com o renascimento dos deuses na idolatria de massa da cultura popular, com a erupção do sexo e violência em todos os cantos dos ubíquos meios de comunicação, o judeu-cristianismo enfrenta o seu mais sério desafio desde o confronto da Europa com o islamismo da Idade Média. O 
paganismo latente da cultura ocidental ressurgiu com toda a sua daimônica vitalidade.

(PAGLIA, 1992:35)

Segundo Paglia (1992), a arte é um lugar sagrado e o que entra nesse espaço se transforma desde o bisonte das cavernas até o cinema de Hollywood, os seres representados criam novas vidas enfeitiçadas e cúlticas, assim ela afirma: “[...] $O$ cinema é o supremo gênero apolíneo, coisa criada e criador de coisas, uma máquina dos deuses." (PAGLIA, 1992:40) A arte como sacrifício também é encontrada nas tragédias e assassinatos da literatura que, em estado de ficção, transfere-se para o recinto do sagrado intensificando nosso prazer e não como lição moral. Paglia também comenta: "[...] O sangue que se derrama será sempre derramado. O ritual na Igreja e no teatro é fixação amoral, afastando a ansiedade pela formalização e paralisação da emoção. O ritual da arte é a lei cruel da dor transformada em prazer." (PAGLIA, 1992:39)

De forma irônica, Márcia $\mathbf{X}$ sugere reflexões sobre experiências sexuais presentes no universo infantil por meio da obra: Os Kaminhas Sutrinhas. São trinta camas de brinquedo que ocupam o chão institucional, ocupadas por duplas ou trios de bonecos sem cabeça e sem roupas, que estão intrincados e movidos mecanicamente por um pedal acionado pelo espectador ao som da música temática da Disneylândia: "It's a small world". Por meio de inquietantes movimentos, os bonecos insinuam práticas sexuais em diversas posições como num manual instrutivo. Encontra-se também, a obra Reino Animal (2000), que consiste em inúmeras bonecas barbies, nuas e também no chão, deitadas sobre gatinhos de pelúcia que movem seus rabos entre suas pernas abertas.

No final do século XVII, a poética do Belo, Bom, Verdade, crenças renascentistas de fundamento metafísico e neoplatônico, passam a ser questionadas, porém, ainda parecemos impregnados desses conceitos. Encontra-se na arte atual, a quebra com a estrutura histórica de objeto de arte e modelo de artista. Confundem-se os parâmetros e juntamente o papel do expectador, que muitas vezes passam a fazer parte da obra. Hoje, distancia-se dos ismos e de possíveis regras tradicionais de leitura de obras, beira-se o abismo e uma tendência, que não vem de hoje, é o grotesco. Porém, essa resistência e negação por meio da quebra de valores tradicionais artísticos, 
aparentemente impenetráveis e indiferentes, podem despertar insaciável desejo a partir da resistência.

A arte pré- histórica tinha intuito de conciliação com a força bruta da natureza, afastando o terror e o medo que esta proporcionava. Já algumas obras da arte contemporânea vêm para ressuscitar esse antigo mal estar, o que ficou lacrado na caixa de pandora. Pelo contrário dos artistas ancestrais, esse espelho negro da arte hoje é para ser visto e revisto sem pretensões de conseguir o que se espera. Nem sempre a razão dá conta de tudo e o vazio proporcionado por essas obras tornam-se formas de potencialidades na arte contemporânea.

Apesar de Márcia X questionar por meio de uma estética geradora de mal-estar, consegue unir bom humor e transgressão, sugerindo ousadas reflexões sobre: sexo, religião, infância, morte, masculino e feminino. Lava, literalmente, terços com sabão em pó e sua alma com coca cola. Desloca e renova sentidos de objetos e ações cotidianos, mostrando-nos como são absurdas muitas das corriqueiras e inofensivas imagens do universo popular, como na performance Ação de Graças (2000-2002) em que a artista calça galos coroados e cravejados de pérolas como fofas e mimosas pantufas. Márcia X enfrentou censuras e vetos em exposições, o que ocorre mesmo após sua morte. Esse gesto só vem a realçar ainda mais a importância de sua obra, que está muito longe de ser indiferente, atraindo-lhe ainda mais atenção. As obras da artista influenciam novas gerações de artistas e dá mérito à história da arte brasileira pós- moderna.

\section{Referência Bibliográfica:}

\section{BAKHTIN, Mikhail. A Cultura Popular na Idade Média e no Renascimento. O} Contexto de François Rabelais. São Paulo: HUCITEC; Brasília: Editora da Universidade de Brasília, 1993;

BASBAUM, Ricardo. "X": Percursos de alguém além de equações. Visitado em 01/06/2008. In: Concinnitas. Revista do Instituto de Artes da UERJ. Disponível em: http://marciax.uol.com.br/mxText.asp?sMenu=4\&sText=43 
CAVALCANTI, Cavalcanti. Estética do desconforto. Visitado em 10/07/2008. In:

Jornal do Brasil - fev.2005. Disponível em:

http://marciax.uol.com.br/mxText.asp?sMenu=4\&sText=36

CYPRIANO, Fábio. Márcia X explora possibilidades múltiplas do erotismo. Visitado em 10/03/2008. In: Folha de São Paulo. Disponível em: http://marciax.uol.com.br/mxText.asp?sMenu=4\&sText=45

FALBO, Giselle. Arte, exposição e ultraje. In: Revista Polêmica. Rio de Janeiro. V 7 (2) - abril/junho 2008. Visitado em 13/07/2008. Disponível em: http://www.polemica.uerj.br/pol21/cimagem/p21_giselle.htm

GOLDBERG, Rose Lee. A Arte da Performance: do futurismo ao presente. São Paulo: Martins Fontes, 2006;

KAYSER, Wolfgang. O grotesco. São Paulo: Perspectiva, 1986;

KONESKI, Anita. Blanchot. Levinas e a arte do Estranhamento. Tese (Doutorado em Curso de Pós- graduação em Literatura) - Universidade Federal de Santa Catarina; Florianópolis;

OLIVEIRA, Márcia. Márcia por Márcia. In: Márcia X. Visitado em 03/07/2008.

Disponível em: http://marciax.uol.com.br/mxText.asp?sMenu=3\&sText=16

PAGLIA, Camille. Personas Sexuais: arte e decadência de Nefertite a Emily Dickinson. São Paulo: Companhia das Letras, 1992;

PIANOWSKI, Fabiane. O corpo como arte; Günter Brus e o acionismo vienense. In: Revista Observaciones Filosóficas. Madrid. n5, 2007. Disponível em: http://www.observacionesfilosoficas.net/ocorpocomoarte.html

RUSSO, Mary J. O grotesco feminino: risco excesso e modernidade. Rio de Janeiro: Rocco, 2000;

SILVA, Márcio. O Local da Diferença. São Paulo: Editora 34, 2005;

SODRÉ, Muniz. A comunicação do grotesco. Um ensaio sobre a cultura de massa no Brasil. Petrópolis: Vozes, 1973. $3^{\text {a }}$. Ed.; 